\title{
Analisis Waktu Tunggu Rawat Jalan di Rumah Sakit Umum Daerah Dr Achmad Darwis Suliki Tahun 2019
}

\author{
Suspenti Dewi ${ }^{1}$, Rizanda Machmud², Yuniar Lestari²
}

\begin{abstract}
Abstrak
Waktu tunggu rawat jalan di RSUD dr. Acmad Darwis Suliki masih menjadi permasalahan, hasil survey awal didapatkan bahwa waktu tunggu rawat jalan masih melebihi SPM rawat jalan yang ada yaitu < 60 menit. Hal ini akan berdampak pada kepuasan pasien terhadap pelayanan yang diterima. Tujuan: Menganalisis waktu tunggu rawat jalan di RSUD dr. Achmad Darwis Suliki tahun 2019. Metode: Penelitian ini adalah studi kualitatif dengan melakukan wawancara semi terstruktur, Focus Group Discussion, observasi dan telaah dokumen. Pengumpulan data dilakukan dengan wawancara pada sembilan orang informan. Komponen yang diteliti yaitu komponen input (SDM, Standar Prosedur Operasional (SPO)/kebijakan dan sarana prasarana), komponen proses (pendaftaran, menyiapkan dokumen rekam medis, pemeriksaan) dan komponen output. Hasil: Jumlah SDM masih kurang dan kedisiplinan petugas khususnya tenaga medis juga masih kurang, SPO rekam medis belum terlaksana secara optimal karena kurangnya kedisiplinan petugas dalam melaksanakan SPO, sedangkan SPO untuk rawat jalan belum ada. Ketersediaan sarana prasarana masih belum mencukupi. Proses pendaftaran terkendala karena jumlah komputer yang kurang. Menyiapkan dokumen rekam medis belum sesuai dengan standar waktu yang telah ditetapkan karena kurangnya petugas dan SPO yang belum terlaksana dengan baik. Waktu tunggu rawat jalan masih belum sesuai standar karena masih melebihi waktu 60 menit. Simpulan: Waktu tunggu rawat jalan di RSUD dr. Achmad Darwis Suliki tahun 2019 belum sesuai standar. Disarankan agar pihak rumah sakit dapat meminimalisasi waktu tunggu rawat jalan dengan penambahan petugas, menyusun SPO, melakukan monitoring dan evaluasi, melengkapi sarana prasarana.
\end{abstract}

Kata kunci: rawat jalan, rumah sakit, waktu tunggu

\begin{abstract}
The waiting time for outpatient treatment at RSUD dr. Acmad Darwis Suliki is still a problem, the initial survey results found that outpatient waiting time still exceeds the existing outpatient MSS of lessthan sixty minutes. Objectives: To analyzed the outpatient waiting time at the RSUD dr. Achmad Darwis Suliki in 2019. Methods: This was a qualitative research by conducting semi-structured interviews, FGD, observation and document review. Data collection was carried out by interviewing nine informants. The components studied were input components (human resources, standart operational procedure/ policy and infrastructure), process components (registration, preparing medical records, examinations) and output components. Results: The number of human resources was still lacking of and the discipline of officers, especially medical personnel, was still lacking, the standard operating procedure of medical records had not been carried out optimally due to the lack of discipline of officers in implementing Standard Operating Procedure, while there was no Standard Operating Procedure for outpatient care. The availability of infrastructure is still inadequate. The registration process was constrained because of the lack of computers. Preparing medical record documents not in accordance with the set time standards due to lack of staff and Standard Operatig Procedure that have not been implemented properly. Outpatient waiting time was still not according to the standard because it still more than sixty minutes. Conclusion: The waiting time for outpatient care at RSUD dr. Achmad Darwis Suliki in 2019 do not meet the standards.
\end{abstract}

Keywords: hospital, outpatient, waiting time 
Affiliasi penulis: Prodi Magister Kesehatan Masyarakat, Fakultas Kedokteran, Universitas Andalas, Padang, Indonesia 2. Bagian IImu Kesehatan Masyarakat Fakultas Kedokteran, Universitas Andalas, Padang, Indoenesia.

Korespondensi : dewisusfenti@gmail.com

Hp: 081363328220

\section{PENDAHULUAN}

Waktu tunggu pasien didefinisikan sebagai lamanya waktu yang diperlukan pasien mulai dari mendaftar sampai dilayani oleh dokter spesialis, idealnya adalah kurang dari 60 menit ( $<1$ jam). Hal ini sesuai dengan Keputusan Menteri Kesehatan Republik Indonesia Nomor 129/Menkes/SK/II/2008 tentang Standar Pelayanan Minimal (SPM) Rumah Sakit. ${ }^{1}$

Kualitas pelayanan kesehatan yang diberikan pada pasien hendaknya dapat dicermati dan disikapi dengan sebaik mungkin agar pasien sebagai pelanggan rumah sakit dapat setia/loyal terhadap rumah sakit. Salah satu aspek yang perlu ditingkatkan kualitasnya adalah aspek pelayanan rawat jalan. ${ }^{2}$ Unit rawat jalan adalah gerbang masuk pasien menuju rumah sakit disamping unit gawat darurat. Angka kunjungan rawat jalan melebihi kunjungan gawat darurat. $^{3}$

Kecendrungan masyarakat terhadap pelayanan poliklinik semakin meningkat untuk mendapatkan pelayanan pengobatan yang praktis sekali datang dan pada hari itu juga mendapatkan pelayanan yang lengkap (one day care). ${ }^{4}$

Berdasarkan hasil wawancara pendahuluan dengan kepala ruangan rawat jalan di RSUD dr. Achmad Darwis Suliki, waktu tunggu pelayanan rawat jalan memang tergolong cukup lama yang disebabkan oleh beberapa faktor. Umumnya pasien mendapatkan pelayanan dokter setelah menunggu lebih dari 60 menit sejak mendaftar. Berdasarkan hasil wawancara dengan 8 orang pasien di poliklinik rawat jalan, mereka mengatakan bahwa telah menunggu lebih dari satu jam tetapi belum diperiksa oleh dokter.

Berdasarkan hal diatas, perlu dilakukan suatu analisis mengenai waktu tunggu rawat jalan di RSUD dr. Achmad Darwis Suliki tahun 2019.

\section{METODE}

Jenis penelitian ini adalah studi kualitatif, dengan menganalisis bagaimana komponen input, process dan output yang bertujuan untuk mendapatkan gambaran secara mendalam tentang penyebab lamanya waktu tunggu rawat jalan di RSUD dr. Achmad Darwis Suliki tahun 2019. Informan dipilih dengan teknik purposive sampling yang terdiri dari Kasi pelayanan medis, kepala instalasi rawat jalan, kepala ruangan rawat jalan, kepala ruangan rekam medik, perawat poliklinik dan petugas pendaftaran.

\section{HASIL}

\section{Komponen Input, Sumber Daya manusia, Kecukupan SDM}

Berdasarkan Permenkes nomor 56 tahun 2014 jumlah pegawai di RSUD dr. Achmad Darwis Suliki belum mencukupi. Pada awal tahun 2019 telah dilaksanakan rekrutmen pegawai untuk memenuhi kekurangan tenaga seperti dokter umum, perawat, bidan dan tenaga penunjang lainnya. ${ }^{5}$

Untuk dapat terlaksananya pelayanan rawat jalan dengan baik perlu didukung oleh jumlah ketenagaan yang cukup. Oleh karena itu RSUD dr. Achmad Darwis berupaya untuk memenuhi kebutuhan tenaga, namun sampai saat ini masih belum mencukupi.

Berdasarkan telaah dokumen, observasi, wawancara semi terstruktur didapatkan hasil bahwa ketersediaan tenaga di RSUD dr. Achmad Darwis belum mencukupi, oleh karena itu perlu penambahan seperti dokter spesialis kebidanan/kandungan dan spesialis anak yang ada hanya satu orang. Untuk rumah sakit kelas $\mathrm{C}$, standar minimal ketersediaan dokter spesialis pada poliklinik pelayanan dasar yaitu masing-masing dua orang. Demikian juga untuk perawat poliklinik, belum semua mempunyai perawat penanggung jawab tetap seperti pada poliklinik syaraf. Untuk petugas rekam medis khususnya bagian penyimpanan masih kurang sehingga terkadang kepala ruangan harus turun tangan untuk membantu disaat-saat pasien ramai. 


\section{Kedisiplinan Petugas}

Berdasarkan hasil wawancara tentang kedisipilinan petugas rawat jalan di RSUD dr. Achmad Darwis Suliki diperoleh informasi bahwa belum semuanya petugas datang tepat pada waktunya sehingga berpengaruh terhadap pelayanan.

Hasil wawancara observasi, telaah dokumen dan FGD tentang kedisiplinan petugas di poliklinik RSUD dr. Achmad Darwis Suliki didapat kesimpulan bahwa untuk perawat umumnya sudah disiplin dalam memberikan pelayanan ditandai dengan jam kedatangan yang sudah sesuai dengan jam dimulainya pelayanan di poliklinik namun yang bermasalah yaitu pada jam kedatangan dokter untuk memulai pelayanan yang sering terlambat. Untuk mengatasi hal ini sebaiknya atasan melakukan evaluasi terhadap jam kedatangan dan diterapkan sistim reward and punishment sehingga dapat meningkatkan kedisiplinan kerja karyawan.

\section{SPO/Kebijakan}

Standar Prosedur Operasional (SPO) di RSUD dr. Achmad Darwis Suliki belum tersedia dengan lengkap, terutama di poliklinik rawat jalan belum ada SPO. SPO di rawat jalan yang berhubungan dengan waktu tunggu misalnya tentang pelayanan pada pasien baru, SPO pelayanan pasien lama/kontrol ulang, SPO tentang persiapan pasien operasi elektif, SPO pemindahan pasien ke ruang rawat inap dan lain-lain. Untuk rekam medis sudah ada, namun pelaksanaannya belum optimal.

Berdasarkan telaah dokumen, observasi dan wawancara semi terstruktur tentang SPO di instalasi rawat jalan RSUD dr. Achmad Darwis Suliki didapatkan bahwa SPO sudah ada tetapi hanya SPO rekam medik, namun pelaksanaannya belum optimal, karena beban kerja yang tinggi misalnya untuk petugas penyimpanan hanya dua orang, tidak jarang mereka salah memasukkan rekam medis tidak sesuai dengan urutan nomor, akibatnya untuk pencarian berikutnya menjadi sulit. Tidak hanya itu SPO tentang pengembalian DRM juga sering tidak terlaksana dengan baik sesuai waktu yang ditetapkan karena kelalaian petugas rawat inap atau rawat jalan. Untuk rawat jalan belum ada SPO. Pihak yanmed dan keperawatan seharusnya menyegerakan penyusunan SPO.

\section{Kebijakan}

Berdasarkan telaah dokumen, observasi dan wawancara semi terstruktur tentang kebijakan waktu tunggu di instalasi rawat jalan RSUD dr. Achmad Darwis Suliki didapatkan bahwa kebijakan itu sudah diatur menurut Peraturan Bupati Lima Puluh Kota Nomor 117 Tahun 2016 tentang Standar Pelayanan Minimal Badan Layanan Umum Daerah RSUD dr. Achmad Darwis dengan berpedoman kepada SPM rumah sakit yaitu Keputusan Menteri Kesehatan no. 129/Menkes/SK/II/2008. ${ }^{6.1}$ Kebijakan tersebut sudah disosialisasikan kepada petugas rawat jalan.

\section{Sarana prasarana}

Peningkatan kuantitas dan kualitas sarana prasarana di poliklinik rawat jalan di RSUD dr. Achmad Darwis Suliki harus diperhatikan agar dapat meminimalisasi waktu tunggu pasien. Beberapa sarana prasarana masih diperlukan untuk proses pelayanan poliklinik.

Berdasarkan hasil wawancara, observasi dan FGD dapat disimpulkan bahwa ketersediaan sarana prasarana di RSUD dr. Achmad Darwis belum mencukupi seperti komputer, rak penyimpanan status, alat pengeras suara, timbangan bayi, set TV, Nurse station, tensi meter. Sarana prasarana perlu dilengkapi untuk kelancaran proses pelayanan sehingga waktu tunggu jadi minimal. Di rumah sakit daerah seperti RSUD dr. Achmad Darwis, pengadaan barang harus sesuai dengan perencanaan. Oleh karena itu sebaiknya bagian sarpras betul - betul memperkirakan atau menghitung kebutuhan sarana secara akurat. Tidak hanya sarana, prasarana juga perlu dilengkapi seperti SIMRS yang terkoneksi ke poliklinik.

\section{Komponen Proses}

- Pendaftaran

Proses pendaftaran pasien yang akan berobat ke poliklinik rawat jalan di RSUD Suliki masih menggunakan sistem manual dan masih terkendala oleh beberapa hal, misalnya kurangnya komputer sehingga pasien menunggu lama khususnya pasien 
BPJS yang harus di seleksi berkas pendaftarannya1. dan diprintkan SJP nya. Walaupun petugas sudah bekerja sesuai SPO namun pelaksanaannya belum optimal.

Hasil dari wawancara dengan informan dan dari hasil observasi tentang proses pendaftaran rawat jalan di RSUD dr. Achmad Darwis diperoleh informasi bahwa pendaftaran menjadi lama apabila pasien ramai, puncaknya sekitar jam 08.00 - 09.00 wib. Pasien BPJS lebih lama menuggu dibanding pasien umum, karena harus menunggu SJP di print sedangkan komputer hanya tersedia 2 buah. Saat ini diberlakukan sistem sidik jari untuk pasien yang akan mendapatkan pelayanan rawat jalan untuk menghindari penyalahgunaan kartu BPJS sehingga membuat waktu pendaftaran semakin panjang.

\section{b. Menyiapkan dokumen rekam medis}

Semakin sedikit waktu yang terpakai untuk menyiapkan dokumen rekam medis maka waktu tunggu pelayanan akan semakin pendek.

Hasil dari wawancara dengan informan dan dari hasil observasi tentang menyiapkan dokumen rekam medis poliklinik rawat jalan RSUD dr. Achmad Darwis diperoleh kesimpulan bahwa proses menyiapkan dokumen rekam medis belum sesuai standar yaitu < 10 menit, hal ini terkendala oleh kurangnya kurir dan petugas penyimpanan, ruang penyimpanan yang berjauhan dan SPO tidak terlaksana sesuai dengan yang seharusnya yang disebabkan oleh kedisiplinan petugas dalam bekerja sesuai SPO masih kurang.

\section{c. Pemeriksaan}

Pemeriksaan terhadap pasien di poliklinik diawal dengan pemeriksaan oleh perawat di poliklinik tujuan seperti pemeriksaan tekanan darah dan anamnesa, kemudian pasien menunggu untuk diperiksa dokter.

Hasil dari wawancara, observasi dan FGD pemeriksaan di poliklinik rawat ralan RSUD dr. Achmad Darwis Suliki dapat disimpulkan bahwa yang menjadi masalah yaitu jam dimulainya pemeriksaan masih lama yang disebabkan oleh keterlambatan kedatangan dokter. Umumnya dokter RSUD dr. Achmad Darwis menempuh jarak kira - kira $25 \mathrm{~km}$ menuju rumah sakit. Pelayanan belum dapat dimulai sesuai dengan jam pelayanan yang telah ditetapkan.

\section{Komponen Output}

Output merupakan elemen yang dihasilkan dari berfungsinya proses dalam sistem. Standar waktu tunggu rawat jalan di RSUD dr. Achmad Darwis telah ditetapkan namun pada kenyataannya pasien masih menunggu lama melebihi dari waktu standar yang telah ditetapkan tersebut.

Hasil dari wawancara, observasi dan FGD tentang komponen output waktu tunggu di Poliklinik Rawat Jalan RSUD dr. Achmad Darwis Suliki dapat disimpulkan bahwa waktu tunggu rawat jalan di instalasi rawat jalan RSUD dr. Achmad Darwis Suliki belum sesuai standar yaitu kurang dari 60 menit. Hal ini belum bisa terlaksana karena berbagai faktor yang mempengaruhi, seperti sarana yang belum mencukupi, waktu penyelenggaraan RM yang melebihi standar dan pelayanan dokter yang tidak dimulai sesuai jam pelayanan yang telah ditetapkan. Untuk itu diperlukan kedisiplinan petugas poliklinik baik perawat maupun dokter, kemudian diperlukan juga penambahan tenaga dan sarana. Disamping itu harus ada koordinasi antar pertugas mulai dari petugas pendaftaran, harus berkomitmen agar pelayanan poliklinik dapat terlaksana sesuai harapan pelanggan.

\section{PEMBAHASAN}

\section{Komponen Input}

- Sumber Daya manusia

Sumber Daya Manusia (SDM) atau tenaga merupakan aset penting dalam suatu organisasi dan motor penggerak proses manajemen. Tenaga dalam penelitian ini adalah pegawai atau personel yang terdiri dari semua anggota organisasi yang terlibat dalam alur pelayanan unit rawat jalan di RSUD dr. Achmad Darwis Suliki.

\section{1) Kecukupan}

Ketersediaan tenaga di RSUD dr. Achmad Darwis belum mencukupi, oleh karena itu perlu penambahan seperti dokter spesialis kebidanan/kandungan dan spesialis anak yang ada hanya 1 orang. Untuk rumah sakit kelas $\mathrm{C}$, standar minimal ketersediaan dokter spesialis pada poliklinik pelayanan dasar yaitu masingmasing 2 orang. ${ }^{5}$ 
Demikian juga untuk perawat poliklinik, belum semua mempunyai perawat penanggung jawab tetap seperti pada poliklinik syaraf. Sedangkan angka kunjungan poli syaraf cukup banyak. Poliklinik Penyakit Dalam hanya mempunyai satu orang perawat, sedangkan rata-rata pasien perhari yaitu \pm 40 orang. Begitu juga untuk Poliklinik Bedah dengan ratarata jumlah pasien perhari melebihi 30 orang dengan berbagai tindakan, sedangkan perawat yang bertugas hanya satu orang, tentu akan mengakibatkan beban kerja yang melebihi dari yang seharusnya. Menurut Oche dan Adamu (2013), penambahan tenaga kesehatan diyakini dapat mengurangi lama waktu tunggu dan dapat meningkatakan kepuasan pasien atas pelayanan kesehatan yang diterima. ${ }^{7}$ Penelitian ini juga sejalan dengan penelitian Fauzan (2017) di RSUD Adnaan WD yang mengatakan bahwa faktor yang menyebabkan waktu tunggu menjadi lama yaitu karena kurangnya tenaga kesehatan. ${ }^{8}$

Petugas rekam medis juga masih kurang. Di RSUD dr. Achmad Darwis Suliki jumlah petugas rekam medis yaitu sebanyak 15 orang, dengan rincian sebagai kepala ruangan satu orang, di Bagian Administrasi dan Registrasi lima orang, medikolegal satu orang dan bagian manajemen Rekam Medik dan Informasi Kesehatan (RMIK). Menurut Menteri Pendayagunaan Aparatur Negara nomor 30 tahun 2013 tentang jabatan fungsional perekam medis dan angka kreditnya, menyatakan bahwa formasi jabatan fungsional perekam medis untuk rumah sakit tipe C adalah 30 orang tenaga terampil dan 6 orang tenaga ahli. ${ }^{9}$ Menurut penelitian Bustami et al (2015) menunjukkan bahwa waktu tunggu pelayanan pasien yang lama disebabkan oleh jumlah pasien yang banyak, kurangnya petugas di loket pendaftaran, keterbatasan ruangan dan keterbatasan SDM. ${ }^{10}$

\section{- Kedisiplinan}

Kedisiplinan petugas di instalasi rawat jalan RSUD dr. Achmad Darwis Suliki umumnya sudah bagus tetapi bermasalah pada jam kedatangan dokter yang masih terlambat karena faktor jarak tempuh menuju rumah sakit lumayan jauh $>25 \mathrm{~km}$. Disamping itu rumah sakit juga tidak memberikan sanksi disiplin bagi petugas yang terlambat datang. Menurut studi penelitian Laeliyah dan Subekti (2015), faktor yang mempengaruhi waktu tunggu pelayanan pasien rawat jalan di RSUD Kabupaten Indramayu diantaranya adalah kurangnya kedisiplinan dalam memulai dan mengakhiri pelayanan kepada pasien di rawat jalan, kurangnya rasa kerjasama yang terjalin antar para petugas dalam melaksanakan pelayanan di rawat jalan (petugas rekam medis, petugas poliklinik, perawat dan dokter) sekaligus kesadaran para petugas akan pentingnya waktu tunggu pelayanan pasien di rawat jalan. Untuk mengatasi masalah tersebut dapat dilakukan dengan meningkatkan kedisiplinan para petugas dan menjalin kerjasama antar para petugas (petugas rekam medis dan petugas poliklinik seperti perawat dan dokter) dalam melaksanakan pelayanan di rawat jalan kepada pasien. ${ }^{11}$

Dalam upaya mendisiplinkan petugas di RSUD dr. Achmad Darwis telah menerapkan sistem absensi finger dan pelaksanaan apel pagi, namun hal tersebut belum mencapai hasil yang maksimal.

\section{SPO}

SPO di RSUD dr. Achmad Darwis sudah ada tetapi hanya SPO rekam medik, tetapi pelaksanaanya belum optimal, misalnya tentang SPO pengembalian rekam medik rawat inap yaitu $2 \times 24$ jam setelah pasien pulang atau dirujuk kecuali untuk kebutuhan autopsi, kenyataannya masih ada rekam medik yang belum kembali sesuai waktu yang telah ditetapkan sesuai SPO, akibatnya sewaktu pasien kontrol ke poliklinik, rekam medis tidak ditemukan di rak penyimpanan. Pengembalian dari rawat jalan juga belum sesuai SPO. Petugas poliklinik tidak mengembalikan Dokumen Rekam Medik (DRM) dua jam setelah pelayanan. Tidak jarang petugas kurir yang datang menjemput ke poliklinik setiap harinya. Hal ini tentu akan berpengaruh terhadap waktu penyelenggaraan rekam medis pasien rawat jalan.

Standar Prosedur Operasional (SPO) dan pedoman merupakan unsur terpenting dalam pelaksanaan suatu kegiatan. Di RSUD dr. Achmad Darwis Suliki SPO untuk dirawat jalan belum ada sehingga bila ada petugas penanggung jawab salah satu poliklinik berhalangan untuk masuk dinas maka 
petugas pengganti merasa kesulitan untuk menggantikan karena belum adanya SPO untuk pelayanan pasien poliklinik. Menurut Handoko (2012), SPO berguna untuk menghemat usaha managerial, memudahkan pendelegasian wewenang dan menempatkan tanggung jawab, memudahkan pengawasan, memungkinkan penghematan personalia dan membantu kegiatan koordinasi. ${ }^{12}$

Berdasarkan Undang-Undang RI no. 44 tahun 2009 menyatakan bahwa rumah sakit wajib memiliki SPO dalam menyelenggarakan dan melaksanakan berbagai kegiatan dan fungsi pelayanan yang dibuat oleh sarana pelayanan tersebut. ${ }^{13}$ Karena tidak adanya SPO, maka tidak dapat dikatakan pelayanan kesehatan sudah sesuai prosedur atau belum. ${ }^{13}$ Menurut Sabarguna (2008), suatu pelayanan yang dijalankan perlu adanya standar pelayanan yang dibuatkan dalam rangka mencapai tujuan. ${ }^{14}$ Penelitian ini juga didukung oleh penelitian Laeliyah dan Subekti (2015) di RSUD Kabupaten Indramayu, yang menyatakan bahwa selain faktor jumlah pasien rawat jalan dan penyediaan berkas rekam medis pasien rawat jalan, hal penting yang mempengaruhi waktu tunggu pelayanan pasien rawat jalan adalah dari pihak RSUD Kabupaten Indramayu sendiri tidak adanya manajemen membuat regulasi dalam bentuk prosedur tetap / SOP, terutama dalam hal penetapan standar waktu tunggu pasien untuk mendapatkan pelayanan rawat jalan. ${ }^{11}$ Penelitian ini sejalan dengan penelitian Nursanti et al (2018), yang menyatakan bahwa hal yang mempengaruhi waktu tunggu antara lain yaitu belum adanya SPO (standar prosedur operasional). ${ }^{15}$

\section{Kebijakan}

Berdasarkan hasil penelitian diketahui bahwa di RSUD dr. Achmad Darwis kebijakan tentang SPM rumah sakit telah diatur dalam bentuk Peraturan Bupati nomor 117 tahun 2016 tentang SPM BLUD dr. Achmad Darwis Suliki. ${ }^{6}$ Kebijakan tersebut telah mengacu pada Keputusanan Menteri Kesehatan Republik Indonesia Nomor 129/Menkes/SK/II/2008. Salah satunya mengatur tentang standar waktu tunggu rawat jalan yaitu $\leq 60$ menit. ${ }^{1}$ Pihak manajemen telah melakukan sosialisasi kebijakan tersebut, namun belum ada monitoring dan evaluasi terhadap pelaksanaannya. Untuk terlaksananya SPM sesuai standar sebaiknya ada rapat koordinasi antara petugas poliklinik dan pihak manajemen untuk membahas kendala yang dihadapi dalam mencapai standar yang telah ditetapkan.

Kebijakan dalam waktu tunggu rawat jalan diatur dalam Keputusanan Menteri Kesehatan Republik Indonesia Nomor 129/Menkes/SK/II/2008 tentang Standar Pelayanan Minimal (SPM) Rumah Sakit. ${ }^{1}$ Meminimalisasi waktu tunggu rawat jalan bertujuan untuk meningkatkan kepuasan pasien sehingga mutu pelayanan meningkat dan pasien loyal terhadap rumah sakit.

Kebijakan adalah keputusan tetap yang dicirikan oleh konsistensi dan pengulangan (repetitiveness) tingkah laku dari mereka yang membuat dan dari mereka yang mematuhi keputusan tersebut. ${ }^{16}$ Menurut Handoko (2012) salah satu bentuk kebijakan yang dapat dibuat dalam bentuk yang lebih terperinci adalah prosedur standar atau Standard Operating Procedure (SOP). Kebijakan dapat dibuat secara formal dan informal oleh para manajer puncak suatu organisasi. ${ }^{12}$

\section{Sarana Prasarana}

Sarana Di RSUD dr. Achmad Darwis khususnya di poliklinik rawat jalan masih banyak yang perlu dilengkapi untuk memperlancar proses pelayanan sehingga waktu tunggu semakin minimal. Untuk sarana di poli anak seperti timbangan bayi, kemudian untuk poli kebidanan set ganti verban hanya ada satu set, tensi meter hanya satu buah dan tidak adanya pengeras suara. Kursi tunggu juga belum mencukupi. Kurangnya tempat duduk yang ada di ruang tunggu poliklinik menyebabkan waktu tunggu menjadi lama karena pasien harus menunggu di luar area poliklinik, sedangkan di poliklinik tidak tersedia alat pengeras suara sehingga terkadang pasien tidak tahu jika namanya sudah dipanggil untuk diperiksa dokter. Permasalahan terbatasnya sarana yang ada sehingga pasien harus menunggu di luar juga ditemukan oleh Patel dan Patel (2017). ${ }^{17}$ Penelitian ini juga sejalan dengan penelitian yang dilakukan oleh Keles et al (2017) di RSUD dr. Samratulangi Tondano, yang mengatakan bahwa faktor yang paling dominan 
yang mempengaruhi waktu tunggu yaitu faktor sarana prasarana. ${ }^{18}$

Prasarana sudah hampir mencukupi. Dokter atau pasien yang datang tidak perlu susah mencari tempat parkir, karena di RSUD dr. Achmad Darwis Suliki sudah tersedia tempat parkir yang cukup luas dan dekat dengan poliklinik. Rumah sakit juga sudah memiliki sumber air sendiri berupa sumur bor dan air PAM. Jika terjadi pemadaman listrik, rumah sakit juga sudah mempunyai genset, sehingga pelayanan tetap berjalan walaupun listrik mati.

Agar proses pelayanan rawat jalan terlaksana dengan lancar maka diharapkan agar rumah sakit melengkapi sarana sesuai dengan standar yang telah ditetapkan dan membuat perencanaan dengan menghitung jumlah kebutuhan untuk masa yang akan datang secara tepat, karena untuk pengadaan barang di rumah sakit umum daerah harus sesuai dengan perencanaan yang telah dibuat.

\section{Komponen Proses}

- Pendaftaran

Berdasarkan hasil penelitian di RSUD dr. Achmad Darwis Suliki didapatkan bahwa, pendaftaran pasien akan bermasalah jika pasien ramai dan terjadi penumpukan pasien, akibatnya pasien akan lama menunggu. Pasien yang mendaftar dengan menggunakan kartu BPJS akan menunggu waktu pendaftaran lebih panjang dibanding pasien umum. Hal ini terjadi karena pasien BPJS harus menyerahkan berkas kelengkapan pendaftaran seperti surat rujukan dan kartu BPJS. Pihak BPJS mengharuskan pasien melakukan verifikasi sidik jari. Verifikasi sidik jari ini bertujuan untuk menghindari penyalahgunaan kartu BPJS. Hasil penelitian ini sejalan dengan penelitian yang dilakukan oleh Nursanti et al (2018), yang mengatakan bahwa waktu tunggu lebih lama pada pasien BPJS dibanding pasien umum. Hal tersebut disebabkan karena petugas harus melakukan verifikasi berkas pasien BPJS. ${ }^{15}$

Di RSUD dr. Achmad Darwis Suliki masih menggunakan sistem pendaftaran manual, untuk masa yang akan datang sudah ada rencana untuk melakukan pendaftaran online. Sistem pendaftaran manual membuat pasien harus datang dan antri untuk mendaftar. Menurut Susanti et al (2015), sistem antrian dan pendaftaran akan menjadi lebih baik jika menggunakan sistem appointment registration. ${ }^{19}$

Ditempat pendaftaran sering ditemui permasalahan seperti antrian yang panjang atau pasien yang menumpuk. Apabila waktu tunggu di pendaftaran lama maka akan mempengaruhi lama waktu pelayanan medis pasien keseluruhan dan selanjutnya akan mempengaruhi kepuasan pasien. Menurut penelitian yang dilakukan oleh Musinguzi (2013), pasien menghabiskan sebagian besar waktu dalam menunggu untuk mendapatkan pelayanan. Bagian pendaftaran merupakan salah satu yang paling menyita waktu dengan besarnya jumlah pasien yang mengantri sehingga memperlambat pelayanan. ${ }^{20}$ Persyaratan pendaftaran yang tidak lengkap juga menjadi masalah yang ditemui di loket pendaftaran. ${ }^{21}$ Waktu tungggu dalam antrian pada jam sibuk pelayanan di loket pendaftaran tertinggi mencapai 58,2 menit. ${ }^{22}$ Penelitian oleh Bustami et al (2015) juga menemukan beberapa masalah dalam rangkaian kegiatan administrasi dan rekam medis yang mengakibatkan memanjangnya waktu tunggu, antara lain banyaknya jumlah pasien, kurangnya petugas di loket pendaftaran dan loket BPJS, gangguan koneksi internet dan pendistribusian rekam medis yang terlambat. $^{10}$

Untuk mengatasi masalah antrian di loket pendaftaran RSUD dr. Achmad Darwis maka sebaiknya disediakan sarana yang mencukupi seperti komputer untuk input data dan mencetak SEP pasien atau memberlakukan sistem pendaftaran on line.

- Menyiapkan Dokumen Rekam Medis

Di RSUD dr. Achmad Darwis proses menyiapkan dokumen rekam medis belum sesuai standar yaitu < 10 menit, hal ini terkendala oleh jumlah petugas. Petugas penyimpanan hanya dua orang dan kurir hanya satu orang, ruang penyimpanan yang berjauhan dan SPO tidak terlaksana sesuai dengan yang seharusnya. Petugas penyimpanan harus bolakbalik mencari rekam medis pada 3 ruangan yang ada, ditambah lagi dengan rak penyimpanan yang terlalu berdekatan, sehingga menyulitkan untuk mengambil rekam medis tersebut. Di RSUD dr. Achmad Darwis 
hanya ada 1 ruangan penyimpanan rekam medis yang menggunakan rollpack sedangkan dua ruangan menggunakan rak. Petugas kurir menumpuk beberapa DRM sebelum didistribusikan ke poliklinik. Hal diatas berbeda dengan penelitian yang dilakukan oleh Darlis (2012) di RSUD Dr. H. Yuliddin Away Tapaktuan yang mengatakan bahwa waktu tunggu pelayanan rekam medis untuk pasien lama dan pasien baru mayoritas pada kategori cepat berdasarkan SPM rawat jalan rumah sakit. ${ }^{23}$

Pelayanan rekam medis yang baik dan bermutu tercermin dari pelayanan yang ramah, cepat serta nyaman. Pelayanan rekam medis rawat jalan dimulai dari tempat pendaftaran pasien sampai memperoleh dokumen rekam medis yang akan digunakan untuk mendapatkan pelayanan kesehatan. Berdasarkan standar penyediaan dokumen rekam medis pelayanan rawat jalan adalah $\leq 10$ menit. $^{24}$

Lama penyediaan dokumen rekam medis merupakan salah satu faktor yang dapat mempengaruhi waktu tunggu secara signifikan karena tanpa adanya dokumen rekam medis maka perawat dan dokter tidak dapat memberikan pelayanan kepada pasien. Di RSUD dr. Achmad Darwis, dokter sudah datang dan siap untuk memulai pelayanan tetapi rekam medis belum sampai diruang periksa. Dalam kondisi seperti ini dokter dan perawat harus menunggu rekam medis untuk dapat memulai pelayanan. Berdasarkan penelitian Melina (2011) di poliklinik RSUD Pasar Rebo, mengatakan bahwa keterlambatan penyelenggaraan berkas rekam medis berhubungan dengan waktu tunggu pasien rawat jalan. ${ }^{25}$

Penanggulangan permasalahan lamanya penyiapan DRM di RSUD dr. Achmad Darwis maka diperlukan penambahan petugas seperti petugas penyimpanan dan kurir, sehingga beban kerja tidak berlebihan. Pelaksanaan SPO juga harus dipantau misalnya dalam penyimpanan kembali DRM harus sesuai dengan nomor urut agar memudahkan dalam pencarian berikutnya. Untuk petugas rawat inap dan rawat jalan harus mengembalikan DRM sesuai dengan jangka waktu yang telah diatur menurut SPO.

\section{- Pemeriksaan}

Di Poliklinik Rawat Jalan RSUD dr. Achmad Darwis Suliki dapat disimpulkan bahwa yang menjadi masalah yaitu jam dimulainya pemeriksaan masih lambat yang disebabkan oleh keterlambatan kedatangan dokter dari yang seharusnya. Umumnya dokter menempuh jarak yang jauh untuk menuju ke rumah sakit. Pemeriksaan dokter berlangsung ratarata lama satu pasien adalah \pm 2 - 8 menit.

Keluhan yang biasa dirasakan oleh pasien rawat jalan diantaranya waktu tunggu untuk diperiksa dokter, ketersediaan berkas rekam medis, fasilitas penunjang di instalasi rawat jalan dan sistem antrian di poliklinik. ${ }^{26}$ Hasil penelitian lain juga mengungkapkan bahwa faktor yang mempengaruhi kepuasan pasien selain waktu tunggu adalah ketepatan pelayanan yang diberikan dokter. ${ }^{27}$

\section{Komponen Output}

RSUD dr. Achmad Darwis telah memiliki standar waktu tunggu untuk rawat jalan. Standar waktu tunggu rawat jalan menurut SPM rumah sakit yaitu $<60$ menit, namun pada kenyataan yang ditemui waktu tunggu rawat jalan masih melebihi standar yang telah ditetapkan tersebut, dimana waktu tunggu rawat jalan untuk poliklinik kebidanan/kandungan yaitu 100,8 menit, poliklinik penyakit dalam 74,4 menit, poliklinik bedah 108,2 dan poliklinik anak 78,8 menit. Menurut Sabarguna (2008), rumah sakit harus mempunyai standar waktu dalam melakukan pelayanan kesehatan tertentu, dengan adanya standar waktu tersebut diharapakan petugas mempunyai pedoman dalam melaksanakan pelayanan yang diberikan kepada pasien dan mempunyai tujuan untuk mencapai target waktu yang telah ditentukan. ${ }^{14}$

Waktu tunggu merupakan masalah yang selalu menimbulkan keluhan pasien di beberapa rumah sakit termasuk di RSUD dr. Achmad Darwis Suliki sendiri. Rumah sakit yang mengabaikan lama waktu tunggu dalam pelayanan kesehatannya, maka secara totalitas kualitas pelayanan rumah sakit akan dianggap tidak professional yang dapat menurunkan kepuasan pasien dan keluarga pasien. Pada dasarnya setiap rumah sakit dikembangkan untuk memenuhi kebutuhan dan kepuasan pasien sebagai pelanggan, hal ini juga berlaku untuk RSUD dr. Achmad Darwis Suliki. Peningkatan mutu pelayanan kesehatan adalah akses terhadap pelayanan yang ditandai dengan waktu tunggu pasien yang cepat. 
SPM agar tercapai khususnya tentang waktu tunggu rawat jalan di RSUD dr. Achmad Darwis maka diperlukan SDM dengan jumlah yang sesuai dengan kebutuhan rumah sakit, memperhatikan kedisiplinan petugas, didukung dengan sarana prasarana yang mencukupi dan SPO/kebijakan yang dilaksanakan.

\section{SIMPULAN}

Waktu tunggu rawat jalan di RSUD dr. Achmad Darwis belum sesuai dengan Standar Pelayanan Minimal (SPM) rumah sakit yang telah ditetapkan, baik yang disebabkan oleh faktor input, proses maupun output. Jumlah sumber daya manusia atau ketenagaan dipolilinik rawat jalan RSUD dr. Achmad Darwis belum mencukupi, walaupun RSUD dr. Achmad Darwis Suliki sudah melaksanakan proses rekrutmen pegawai diawal tahun 2019. Proses pendaftaran pasien di RSUD dr. Achmad Darwis Suliki sudah dilakukan sesuai SPO namun masih ditemui beberapa kendala misalnya jumlah komputer yang kurang sehingga disaat pasien ramai terjadi penumpukan pasien. Dalam menyiapkan dokumen rekam medis di RSUD dr. Achmad Darwis Suliki masih belum memenuhi standar waktu yang telah ditetapkan karena masih melebihi 10 menit. Hal ini terjadi karena kurangnya petugas kurir, petugas penyimpanan dan ruang penyimpanan yang terpisah.

\section{SARAN}

Rumah sakit juga disarankan untuk mengeluarkan kebijakan dalam bentuk SPO terkait pelayanan di rawat jalan di RSUD dr. Achmad Darwis Suliki, melengkapi sarana prasarana pelayanan rawat jalan seperti pengeras suara dan SIMRS yang terkoneksi ke seluruh ruangan termasuk ke poliklinik rawat jalan sehingga melancarkan proses pelayanan.

\section{UCAPAN TERIMAKASIH}

Terimaksih kepada pihak Manajemen dan staf pelayanan RSUD dr. Achmad Darwis Suliki yang telah memberikan pengetahuan dan informasi sehingga menambah pengalaman bagi penulis. Serta semua pihak yang terlibat dalam menyelesaikan penelitian ini.

\section{DAFTAR PUSTAKA}

1. Kementerian Kesehatan $\mathrm{RI}$ (Kemenkes RI). Peraturan Menteri Kesehatan RI Nomor 129/ Menkes/SK/II/2008 tentang Standar Pelayanan Minimal (SPM) Rumah Sakit. Jakarta: Kemenkes $\mathrm{RI} ; 2008$.

2. Dewi H, Anny RM, Sri K. Tingkat kepuasan pelayanan pasien tentang waktu tunggu di poliklinik Asy-Syifa Kudus. Jurnal IImu Keperawatan dan Kebidanan. 2008; 2(1):1.

3. RSUD dr. Achmad Darwis. Profil RSUD dr. Achmad Darwis Suliki. RSUD dr. Achmad Darwis; 2018.

4. Setiawan A. Pengaruh disiplin kerja dan motivasi terhadap kinerja karyawan pada rumah sakit umum daerah Kanjuruan Malang. Jurnal IImu Manajemen. 2013;1:1245-53.

5. Kemenkes RI. Peraturan Menteri Kesehatan Nomor 56 tahun 2014 tentang Klasifikasi dan Perizinan Rumah Sakit. Jakarta: Kemenkes RI; 2014.

6. Peraturan Bupati Nomor 117 Tahun 2016 tentang SPM BLUD dr. Achmad Darwis Suliki. Sarilamak: Pemda Lima Puluh Kota; 2016

7. Oche M, Adamu H. Determinants of patient waiting time in the general outpatient department of a tertiary health institution in North Western Nigeria. Annals of medical and Health Sciences Research. 2013;3:588-92.

8. Fauzan I. Analisa lama waktu tunggu pelayanan pasien unit rawat jalan di RSUD Adnaan WD Payakumbuh. Jurnal Kesehatan Masyarakat. 2017; 6(5):

9. Menteri Pendayagunaan Aparatur Negara (Menpan) dan Reformasi Birokrasi RI. Peraturan menteri pendayagunaan aparatur negara dan reformasi birokrasi $\mathrm{RI}$ nomor 30 tahun 2013 tentang jabatan fungsional perekam medis dan angka kreditnya. Jakarta: Menpan dan Reformasi Birokrasi Rl; 2013.

10. Bustami M, Rattu AJ, Saerang JS. Analisa lama waktu tunggu pelayanan pasien rawat jalan di balai kesehatan mata masyarakat propinsi Sulawesi Utara. Jurnal e-Biomedik. 2015;1:1-12. 
11. Laeliyah $\mathrm{N}$, Subekti $\mathrm{H}$. Waktu tunggu pelayanan rawat jalan dengan kepuasan pasien terhadap pelayanan di rawat jalan RSUD Kabupaten Indramayu. Jurnal Kesehatan Vokasional. 2015;2: 102-12.

12. Handoko. Manajemen. Yogyakarta: Fakultas Ekonomi dan Bisnis UGM; 2012.

13. Undang-Undang Republik Indonesia Nomor. 44 Tahun 2009 tentang Rumah Sakit. Jakarta: Menteri Hukum dan HAM RI; 2009.

14. Sabarguna. Analisa pemasaran rumah sakit. Yogyakata: Konsorsium Rumah Sakit Islam Jateng-DIY; 2008.

15. Nursanti FJ, Hariyanti T, Harjayanti ND. Faktorfaktor yang mempengaruhi lama waktu tunggu pendaftaran pasien RSU X Malang. Journal of Ners and Midwifery. 2018;5:154-8.

16. Agustino L. Dasar-dasar kebijakan publik. Bandung: Alfabeta; 2017.

17. Patel R, Patel HR. A study on waiting time and outpatient satisfaction at Gujarat Medical Education Research Society Hospital, Valsad Gujarat. International Journal of Community Medicine and Public Health. 2017;4:857-63.

18. Keles II, Kekenusa JS, Rattu AJM. Faktor-faktor yang berhubungan dengan lama waktu tunggu di poliklinik penyakit dalam RSUD Dr. Sam Ratulangi Tondano. Jurnal Universitas Sam Ratulangi Manado. 2017; 2(4):86-97.

19. Susanti Y, Azis Y, Kusnadi D. Pengaruh appointment registration system terhadap waktu tunggu dan kepuasan pasien. Global Medical and Health Communication. 2015;3:40-7.

20. Musinguzi C. Patient waiting time and associated factors at the assessment center. general outpatient department Mulago Hospital Uganda. Thesis Masters of health Services Research Uganda Virus Research Institute. 2013;4(1):1-70.

21. Febriyanti DH. Faktor-faktor yang Mempengaruhi Waktu Tunggu Pendaftaran di TPPRJ RSUD Turejo Semarang [skripsi]. Fakultas Kesehatan, Universitas Dian Nuswantoro; 2013.hlm.1-6.

22. Fuanasari AD, Suparwati A, Wigati PA. Analisis alur pelayanan dan antrian di loket pendaftaran pasien rawat jalan. Jurnal Kesehatan Masyarakat (e-Journal). 2014;2:15-21.

23. Darlis. Tinjauan waktu tunggu pelayanan rekam medis rawat jalan di RSUD Dr. H. Yuliddin Away Tapaktuan Kabupaten Aceh Selatan. Fakultas Kesehatan Masyarakat Universitas Teuku Umar Meulaboh. 2012.hlm.1-41.

24. Dirjen Pelayanan Medik. Petunjuk teknis penyelenggaraan rekam medis. Jakarta: Departemen Kesehatan RI; 2007.

25. Melina DE. Faktor-faktor yang berhubungan dengan waktu tunggu pasien instalasi rawat jalan di lima poliklinik RSUD Pasar Rebo [skripsi]. Depok: Fakultas Kesehatan Masyarakat, Universitas Indonesia; 2011.hlm.1-65.

26. Dewanto A. Pengaruh waktu tunggu terhadap wait satisfaction pasien di instalasi rawat jalan RSAL Dr Ramelan. Jurnal Aplikasi Manajemen Universitas Brawijaya. 2014;12: 248-50.

27. Putri VJ. Hubungan waktu tunggu pelayanan dengan kepuasan pasien BPJS di poli rawat jalan Rumah Sakit Islam Ahmad Yani Surabaya. Global Health Science. 2018;3:387-93. 